\begin{tabular}{|c|c|}
\hline Title & $\begin{array}{l}\text { An efficient PEGylated gene delivery system with improved targeting : Synergism between octaarginine and a } \\
\text { fusogenic peptide }\end{array}$ \\
\hline Author(s) & Khalil, Ikramy A .; Harashima, Hideyoshi \\
\hline Citation & $\begin{array}{l}\text { International journal of pharmaceutics, 538(1-2), 179-187 } \\
\text { https://doi.org/10.1016/.ijpharm.2018.01.007 }\end{array}$ \\
\hline Issue Date & 2018-03-01 \\
\hline Doc URL & http:/hdl.handle.net/2115/2701 \\
\hline Rights & $\begin{array}{l}\text { ○2018, Elsevier. This manuscript version is made avail able under the CC-BY-NC-ND } 4.0 \text { license } \\
\text { http://creativecommons.org/icenses/oy-nc-nd/4.0/ }\end{array}$ \\
\hline Rights(URL) & http://creativecommons.org/icenses/by-nc-nd/4.0/ \\
\hline Type & article (author version) \\
\hline File Information & WoS_84375_Khalil.pdf \\
\hline
\end{tabular}

Instructions for use 
International Journal of Pharmaceutics

Full Length Manuscript

Pharmaceutical Nanotechnology

\title{
An Efficient PEGylated Gene Delivery System with Improved Targeting: Synergism between Octaarginine and a Fusogenic Peptide
}

\author{
Ikramy A. Khalil ${ }^{\mathrm{a}, \mathrm{b}, *}$, Hideyoshi Harashima,

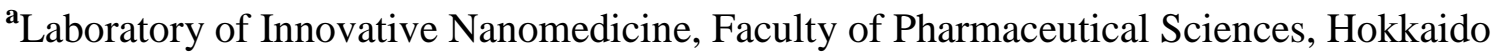 \\ University, Kita 12, Nishi 6, Kita-ku, Sapporo 060-0812, Japan \\ ${ }^{\mathrm{b}}$ Department of Pharmaceutics, Faculty of Pharmacy, Assiut University, Assiut 71526, \\ Egypt
}

*Corresponding authors at: Faculty of Pharmaceutical Sciences, Hokkaido University, Sapporo, Hokkaido, 060-0812, Japan. Tel.: +81 11706 3919; fax: +81 11706 4879. E-mail address: harasima@pharm.hokudai.ac.jp (H. Harashima), ikramy@aun.edu.eg (I.A. Khalil) 


\section{ABSTRACT}

Because of their ability to translocate different cargos into cells, arginine-rich cell penetrating peptides (CPPs) are promising vehicles for drug and gene delivery. The use of CPP-based carriers, however, is hampered by the lack of specificity and by interactions with negative serum components. Polyethylene glycol (PEG) is used to decrease such nonspecific interactions, albeit its use is associated with reduced transfection efficiency. In this study, we describe the development of PEGylated CPP-based gene carrier with an improved targeting and a high transfection activity. The system was prepared by condensing DNA with a polycation followed by coating with a lipid envelope containing the octaarginine (R8) peptide as a model CPP. R8-modified nanoparticles produced high transfection activities, but the efficiency was reduced by PEG shielding. The reduced activity could be fully restored by the addition of a targeting ligand and a $\mathrm{pH}$-sensitive fusogenic peptide. The efficiency of the proposed system is quite high, even in the presence of serum, and shows improved targeting and selectivity. Surprisingly, the effect of the fusogenic peptide was dramatically reduced in the absence of R8. Although shielded, R8 augmented the activity of the fusogenic peptide, suggesting a synergistic effect between the two peptides at the intracellular level.

\section{Keywords:}

Octaarginine; PEG; transferrin; GALA; MEND; nonviral gene delivery 


\section{Introduction}

Gene therapy is a promising approach for treating a wide range of inherited and acquired diseases that are not efficiently cured by conventional medicine (Collins and Thrasher, 2015; Mountain, 2000; Naldini, 2015). Such diseases include cancer, cystic fibrosis, diabetes, hemophilia, infections and degenerative diseases. Gene therapy implies the use of genetic materials as therapeutics to express or to interfere with the synthesis of certain proteins. Successful gene therapy requires the efficient and selective transfer of therapeutic genes, not only to specific cells but to intracellular target sites as well. Genetic materials are not efficiently transferred to target sites in the absence of an appropriate vector. An ideal gene vector should efficiently, specifically, and safely transfer genetic materials to intracellular target sites. This ideal gene vector stays speculative since currently available systems lack one or more of these attributes (Itaka and Kataoka, 2009; Kamiya et al., 2013).

Cationic lipids are commonly used to condense and protect DNA in cationic complexes (lipoplexes) that can be internalized into cells and deliver DNA to intracellular target sites (Tros de Ilarduya et al., 2010; X. X. Zhang et al., 2012). However, the fact that lipoplexes have net positive charges renders them non-specific, since they interact with negatively charged extracellular components (Khalil et al., 2006a; Y. Zhang et al., 2012). In addition, lipoplexes require the use of high amounts of cationic lipids which can lead to cytotoxicity issues (Torchilin et al., 2003). The emerging use of short cell-penetrating peptides (CPPs) in drug and gene delivery represents an attractive potential alternative for replacing cationic lipids, thus increasing the safety profile (Brooks et al., 2005; Fonseca et 
al., 2009; Gupta et al., 2005). CPPs are generally characterized by the presence of positively charged arginine residues and even peptides comprised exclusively of arginine residues have been shown to be as efficient as common protein-derived CPPs (Futaki et al., 2001a). We previously reported on the development of liposomes modified with an octaarginine peptide (R8) that showed efficient and rapid cellular internalization through endocytosis (Khalil et al., 2006b; Khalil et al., 2008). To develop gene carriers based on R8-Lip, the simple mixing of plasmid DNA (pDNA) and liposomes was not sufficient, since the peptide should be freely expressed on the surface to efficiently interact with cell membranes (Khalil et al., 2004). A nanotechnology technique that will permit the topology of the peptide to be controlled to exert its function is clearly needed. To accomplish this, we developed an R8-modified Multi-functional Envelope-type Nano Device (R8-MEND) based on the concept of Programmed Packaging (Khalil et al., 2007; Kogure et al., 2008, 2007, 2004). The MEND is composed of a condensed pDNA core covered with a lipid envelope that is modified with the R8 peptide. This system allows the integration of multiple functional devices in single nanoparticles with appropriate topology control and permits them to exert their function. The R8 modification of the MEND resulted in a high cellular uptake and improved intracellular trafficking after endocytosis (Khalil et al., 2006b; Khalil et al., 2007). The transfection activity of the R8-MEND encapsulating pDNA was comparable to that produced by Adenovirus-mediated transfection with reduced cytotoxicity (Khalil et al., 2007). The R8-MEND successfully transfected liver tissues after systemic administration (Hayashi et al., 2012, 2011; Khalil et al., 2011). It was even more efficient than Lipofectamine reagent in transfecting hair follicles after topical 
administration (Khalil et al., 2007).

Despite the promise of CPPs as tools for improving gene delivery, the non-specificity issue is a common and well characterized disadvantage of cationic CPPs in general (Fonseca et al., 2009; Gupta et al., 2005). Actually, positive CPPs can be internalized with their cargos into most cell types mediated by electrostatic interactions with negative components of the cell surface. Therefore, a strategy directed at decreasing non-specific interactions and increasing the targeting ability of CPP-based gene carriers is clearly needed to extend their applications in gene therapy. While attempting to decrease the extent of non-specific interactions, it should be noted that the transfection activity in target cells must remain high. This is a general dilemma since typical methods used for decreasing non-specific interactions also frequently result in a decreased transfection activity (Hatakeyama et al., 2013). For example, hydrophilic polymers such as polyethylene glycol (PEG) are generally used to stabilize cationic systems. However, PEGylation impairs interaction with cellular membranes leading to an overall reduced activity (Deshpande et al., 2004; Hatakeyama et al., 2013; Remaut et al., 2007; Song et al., 2002). Therefore, an innovative design is needed in which target ability is combined with a high transfection activity.

The goal of this study was to improve the targeting ability of the R8-MEND system while simultaneously maintaining its transfection activity. We propose a strategy in which the system is coated with PEG, to decrease non-specific interactions, and further modified with a targeting ligand, to enhance cellular uptake and impart active targeting ability. In addition, the system is modified with a $\mathrm{pH}$-sensitive fusogenic peptide to enhance the 
endosomal escape. The proposed system, with a net negative charge and a dense PEG coat, shows a high transfection activity that is comparable to that of non-PEGylated R8-MEND. Compared to the original system, the optimized system showed an improved targeting, a higher specificity to cancer cells and an improved serum resistance. This study shows a dual effect of a CPP and a targeting ligand where each component exerts its function at the appropriate step. In addition, CPP and fusogenic peptides show a synergistic effect at the intracellular level.

We believe that PEGylation and adding targeting ability to CPP-based carriers while retaining their high activity has significant implications in the future design of nonviral gene delivery systems. In addition, the use of CPP for the augmentation of fusogenic peptides is a novel strategy that is expected to expand the applicability of these peptides in future medicines. 


\section{Materials and methods}

\subsection{Materials}

Plasmid DNA pCMV-luc (7037 bp) encoding luciferase (pDNA) was amplified in Escherichia coli and purified using an EndoFree Plasmid Mega Kit (Qiagen, Hilden, Germany). Cholesteryl hemisuccinate (CHEMS), human holo-transferrin (Tf), 3-(2pyridyldithio) propionic acid N-hydroxysuccinimide ester (SPDP), dithiothreitol (DTT), 3,3,5-Triiode-L-thyrone (T3), L-thyroxine (T4) and linear polyethyleneimine (PEI) (average MW $750 \mathrm{KDa}$ ) were purchased from SIGMA-Aldrich (St. Louis, MO, USA). Dioleoyl phosphatidylethanolamine (DOPE), cholesterol (Chol), distearyl phosphatidyl ethanolamine-polyethyleneglycol 2000 (DSPE-PEG) and maleimidic DSPE-PEG (DSPEPEG-mal) were purchased from AVANTI Polar Lipids (Alabaster, AL, USA). Stearylated R8 (STR-R8) and cholesterol-GALA (Chol-GALA) were synthesized as described previously (Futaki et al., 2001b; Kakudo et al., 2004). Propidium iodide (PI), sodium deoxycholate (SDOC), L-ascorbate phosphate magnesium salt n-hydrate and chloroquine diphosphate were purchased from WAKO Pure Chemicals (Osaka, Japan). Lipofectamine Plus reagent (LF-Plus), Dulbecco`s modified eagle medium (DMEM) and fetal bovine serum (FBS) were purchased from Invitrogen Corp. (Carlsbad, CA, USA). Luciferase assay reagent and reporter lysis buffer were obtained from Promega Co. (Madison, WI, USA). HeLa human cervix carcinoma cells were obtained from the RIKEN Cell Bank (Tsukuba, Japan).

\subsection{Cell culture}


HeLa cells were cultured in DMEM supplemented with 10\% heat-inactivated FBS, penicillin $(100 \mathrm{U} / \mathrm{mL})$ and streptomycin $(100 \mu \mathrm{g} / \mathrm{mL})$ at $37^{\circ} \mathrm{C}$ in an atmosphere of $5 \% \mathrm{CO}_{2}$ and 95\% humidity. 3T3-L1 cells were cultured in DMEM supplemented with glucose (4.5 g/L), HEPES (10 mM), L-glutamine (4 mM), ascorbate (0.2 mM), T3 (1 nM), T4 (30 nM), and 10\% heat-inactivated FBS. H9C2 cells were cultured in DMEM supplemented with glucose (4.5 g/L), L-glutamine (4 mM), pyruvate (0.11\%) and 10\% heat-inactivated FBS.

\subsection{Preparation of MENDs}

The R8-MEND was prepared by the lipid hydration method as reported previously with minor modifications (Kogure et al., 2004). A diluted solution of PEI (100 $\mu \mathrm{L})$ in 10 mM HEBES buffer (pH 7.4) (HB) was added drop wise under vortexing to a dilute solution of pDNA $(200 \mu \mathrm{L})$. The solution was then allowed to stand at room temperature (RT) for $15 \mathrm{~min}$. The nitrogen/phosphate (N/P) ratio in the final solution is adjusted to 0.8 . Simultaneously, a lipid film was formed by the evaporation of chloroform:ethanol (3:1) solution of lipids (90 nmol) in a round bottom glass tube. The lipid composition was DOPE/Chol/STR-R8 (7:2:1 molar ratio). The core solution (300 $\mu \mathrm{L})$ was added to the glass tube containing the dried lipid film and the tube was rotated gently to allow electrostatic binding between the negative DNA core and the positive lipid film. After 15 min incubation at RT to allow hydration of the lipid film, the tube was sonicated for $\sim 1 \mathrm{~min}$ in a bath type sonicator. The resulting R8-MEND suspension was allowed to stand for 30 min at RT. In the case of a MEND without R8 modification, the lipid film was composed of DOPE/Chol/CHEMS (7:2:2 molar ratio) and the pDNA/PEI core was prepared at an N/P

ratio 4. MENDs containing GALA was prepared in the same manner, except for the 
inclusion of Chol-GALA (2 mol\% of total lipid) in the chloroform:ethanol solution of lipids. PEGylation of different MENDs was performed by a post-modification method. An HB solution containing different amounts of DSPE-PEG was added to the MEND suspension followed by incubation for $30 \mathrm{~min}$ at RT.

\subsection{Transferrin modification}

Transferrin modification of different MENDs was performed as previously described (Sasaki et al., 2008). Tf (final concentration $125 \mathrm{mM}$ ) was reacted with SPDP (final concentration $132 \mathrm{mM}$ ) for $30 \mathrm{~min}$ at RT with moderate shaking. The formed 3-(2pyridinedithio)proprioyl Tf (PDP-Tf) was separated from unreacted SPDP by gel filtration on a Sephadex G-25 Fine column. The PDP-Tf was then reduced by treatment with 100 mM DTT for 30 min at RT. The resulting 3-mercaptopropyl-Tf was purified on a Sephadex G-25 Fine column. The concentration of $\mathrm{Tf}$ in the final solution was determined using a BCA protein assay kit (Pierce, Rockford, IL, USA) using a standard curve prepared using free Tf. Disulfide cross-linking between Tf and MEND was conducted by treating 3mercaptopropyl-Tf with PEGylated MENDs containing 2 mol\% of DSPE-PEG-mal (16 $\mu \mathrm{g}$ Tf per $1 \mu \mathrm{g}$ DNA) at $4^{\circ} \mathrm{C}$ overnight. The resulting Tf-modified MENDs were separated from unreacted Tf by centrifugation at $81000 \mathrm{rpm}$ for 2 hours at $4^{\circ} \mathrm{C}$. The final concentration of DNA in the suspensions was determined by treating the samples with SDOC (final concentration $5 \mathrm{mM}$ ) and PI (final concentration $100 \mu \mathrm{g} / \mathrm{mL}$ ) for $\sim 15 \mathrm{~min}$ at RT in the dark. The fluorescence intensity was then measured (excitation wavelength 535 nm and emission wavelength $620 \mathrm{~nm}$ ) using a standard curve for non-centrifuged MENDs. 


\subsection{Characterization of MENDs}

The diameter and zeta potential of the formed nanoparticles (NPs) were measured using an electrophoretic light-scattering spectrophotometer (Zetasizer; Malvern Instruments Ltd., Malvern, WR, UK).

\subsection{Transfection assay}

HeLa cells were cultured in a 24-well plate (40,000 cells per well) 1 day before transfection. At the transfection time, the culture medium was removed and cells were washed with $500 \mu \mathrm{L}$ DMEM. Samples containing $0.4 \mu \mathrm{g}$ pDNA suspended in $300 \mu \mathrm{L}$ DMEM supplemented with 10\% FBS were added to each well and the cells were incubated for $3 \mathrm{hr}$ at $37^{\circ} \mathrm{C}$. The medium was then removed and $1 \mathrm{~mL}$ of fresh DMEM with $10 \% \mathrm{FBS}$ was added followed by further incubation for $21 \mathrm{hr}$. At the end of the incubation, the medium was removed and the cells were washed with phosphate buffered saline (PBS) 500 $\mu \mathrm{L}$ then solubilized by adding $75 \mu \mathrm{L}$ of Reporter Lysis Buffer. Luciferase activity in the cell lysate was measured in the presence of a Luciferase Assay Reagent by means of a luminometer (Luminescence-PSN, ATTO, Japan). The amount of total proteins in cell lysates was measured using a BCA protein assay kit (Pierce, Rockford, IL, USA). To examine the effect of chloroquine, cells were covered with DMEM containing chloroquine before addition of the MEND samples (chloroquine final concentration $100 \mu \mathrm{M}$ ). Cells were incubated for $3 \mathrm{hr}$, the medium then was replaced with $1 \mathrm{~mL}$ of fresh medium with chloroquine and the incubation was continued for $21 \mathrm{hr}$. To examine the effect of free Tf, 3 mg of free Tf was added to the DMEM solution over cells before the addition of different 
MEND samples. Cells were incubated for $1 \mathrm{hr}$ then the medium was replaced with fresh medium and the cells were further incubated for $23 \mathrm{hr}$. To examine the effect of serum, different volumes of serum was added to the DMEM solution over cells before the addition of the DNA samples. The medium was replaced with fresh medium containing $10 \%$ FBS after $3 \mathrm{hr}$ and the cells were further incubated for $21 \mathrm{hr}$. Transfection using the Lipofectamine Plus reagent were performed as described by the manufacturer. DNA/liposome complexes were formed in the absence of serum then added to cells covered with medium supplemented with different amounts of serum. Briefly, pDNA (0.4 $\mu \mathrm{g})$ was diluted in $21 \mu \mathrm{L}$ DMEM without serum, $4 \mu \mathrm{L}$ of Plus Reagent was added and the suspension then incubated for 15 min at RT. Diluted Lipofectamine $(1 \mu \mathrm{L}$ in $25 \mu \mathrm{L}$ DMEM without serum) was then added to pre-complexed DNA followed by incubation for 15 min at RT. The combined solution was then added to cells covered with $250 \mu \mathrm{L}$ medium with or without different amounts of serum and the cells were incubated for $3 \mathrm{hr}$. The medium was then replaced with $1 \mathrm{~mL}$ of fresh medium with 10\% FBS and the incubation continued for $21 \mathrm{hr}$.

\subsection{Evaluation of cellular uptake}

HeLa cells were cultured in a 6-well plate ( $2 \times 10^{5}$ cells per well) 1 day before transfection. At the transfection time, the culture medium was removed and cells were washed with $1 \mathrm{~mL}$ DMEM. Samples of MENDs labeled with DiD fluorescence (1 mol\% of total lipids) containing $2 \mu \mathrm{g}$ pDNA suspended in $1.25 \mathrm{~mL}$ DMEM supplemented with 10\% FBS were added to each well and the cells were incubated for $3 \mathrm{hr}$ at $37^{\circ} \mathrm{C}$. The medium was then removed and cells were washed with $1 \mathrm{~mL}$ PBS containing $20 \mathrm{U}$ heparin then 
harvested by trypsinization. After centrifugation $\left(15000 \mathrm{rpm}\right.$ at $\left.4^{\circ} \mathrm{C}\right)$, the cell pellet was suspended in PBS and re-centrifuged (three times). Finally, the cells were suspended in PBS and filtered through a nylon mesh before subjected to flow cytometry using FACS caliber (BD Bioscience, San Jose, USA).

\subsection{Statistical analysis}

Comparisons between multiple treatments were made using the one-way analysis of variance (ANOVA), followed by the Bonferroni or the Student-Newman-Keuls test. Pairwise comparisons between treatments were made using a two-tail Student $t$-test. A $p$-value of $<0.05$ was considered significant. 


\section{Results}

\subsection{PEGylation of R8-MEND}

The effect of the addition of PEG on the characteristics and transfection activities of the R8-MEND was examined. The R8-MEND was composed of a negatively charged DNA/PEI condensed core covered with a lipid envelope comprised of DOPE, Chol and STR-R8. The resulting R8-MEND had a diameter of $261 \mathrm{~nm}$ and a net positive charge ( 41 mV) (Table 1). The origin of the net positive charge is the positively charged R8 peptide on the surface of the lipid envelope. The addition of increasing amounts of DSPEPEG to the pre-formed R8-MEND (post-PEGylation) resulted in a significant reduction in the positive charge of the system. R8-MENDs modified with 5-10 mol\% DSPE-PEG were still positive while those modified with 15-20 mol\% DSPE-PEG had a neutral to slightly positive or negative charge. This indicates that the addition of 15 mol\% PEG or more successfully shielded most of the positive charge of R8. The presence of the PEG coat probably decreases the aggregation of NPs since the diameter of the PEGylated R8-MEND was lower compared to the non-modified R8-MEND.

We next examined the transfection activities of the R8-MEND compared to PEGylated R8-MENDs in HeLa cells in the presence of 10\% serum. As expected, the R8MEND had a high transfection activity (Figure 1). This is mainly due to enhanced cellular uptake and controlled intracellular trafficking mediated by R8 and the fusogenic DOPEcontaining lipid envelope (Khalil et al., 2007; Kogure et al., 2004). The addition of PEG decreased the transfection activities in a dose-dependent manner. PEG, at a level of 5 mol\%, 
caused a reduction in gene expression by $~ 2$ orders of magnitude. Increasing the amount of PEG further decreased the activity up to $15 \mathrm{~mol} \%$. Since the aim was to decrease nonspecific interactions of R8-MEND, it was important to define the amount of PEG that is sufficient to shield the positive charge of R8. Figure 1 suggests that 15 mol\% PEG is probably sufficient for shielding most of the positive charge of R8.

\subsection{Mechanism of reduced activity of PEGylated MEND}

We aimed to restore the activity of R8-MEND that is lost by PEGylation without affecting the physicochemical characteristics of the PEGylated R8-MEND. To accomplish this, we needed to identify the mechanism responsible for the reduced activities of PEGylated R8-MENDs. We compared the cellular uptake of R8-MEND and R8-MEND coated with 15 mol\% PEG using flow cytometry (Figure 2A). The cellular uptake was significantly reduced by $\sim 50 \%$ by the addition of PEG. We also examined the transfection activity of the PEGylated R8-MEND in the presence of the endosome disrupting agent chloroquine in an attempt to identify the effect of PEG on endosomal escape. Chloroquine accumulates in endosomes and eventually causes endosome disruption leading to an enhanced cytosolic release of endocytosed carriers (Cervia et al., 2017). Chloroquine would be expected to fully restore the activity if only endosomal escape is impaired. As shown in Figure 2B, the transfection activity of PEGylated R8-MEND is dramatically increased by 2 orders of magnitude in the presence of chloroquine. However, the activity in the presence of chloroquine was lower than that of the R8-MEND by $\sim 8$ fold. This indicates that both cellular uptake and endosomal escape are impaired by PEGylation, the latter being

the more significantly affected step. The effect of chloroquine was consistent with the study 
of cellular uptake inhibition, which confirms the importance of improving endosomal escape as the main step in restoring the high activity. The activity of the R8-MEND without PEG was enhanced by 2.3 fold in the presence of chloroquine. This probably reflects a relatively high endosomal escape of R8-MEND, a result that is consistent with our previous analysis of the intracellular trafficking of the R8-MEND (El-Sayed et al., 2008; Khalil et al., 2007).

\subsection{Effect of transferrin modification}

We hypothesized that the cellular uptake of PEGylated NPs could be improved by the addition of a targeting ligand to the tip of PEG. In addition, the presence of a targeting ligand would be expected to specifically internalize NPs to cells expressing receptors to this ligand. We examined the effect of adding a model targeting ligand; transferrin (Tf), which is a glycoprotein that transports iron into cells. Tf reacts with Tf-receptors (Tf-Rs) on the cell surface and the complexes are internalized into cells via endocytosis (Sharma et al., 2016). Since Tf-Rs are over-expressed in tumor cells, Tf is a promising ligand to actively enhance cellular uptake in tumor cells. To attach Tf to the tip of PEG chains via disulfide bonding, the PEG coat included maleimidic DSPE-PEG (DSPE-PEG-mal). The addition of Tf changed the net surface charge of PEGylated R8-MEND to be negative (Table 2). This confirms that Tf was successfully attached to the PEG. The negative charge increased only slightly by increasing the mol \% of PEG. The diameter of the Tf-modified did not exceed $200 \mathrm{~nm}$, an important parameter for enhancing tumor accumulation after systemic administration based on enhanced permeability and retention (EPR) effects (Hatakeyama et al., 2013). The addition of Tf resulted in a significant increase in the gene expression of R8- 
MEND modified with 10 or 15 mol \% PEG (Figure 3). This improvement is thought to be the result of the enhanced cellular uptake of NPs through Tf/Tf-R interactions. The enhancement by Tf was lower in the case of 20 mol\% PEG. The addition of high amounts

of PEG appears to severely impair endosomal escape since enhancing cellular uptake through Tf addition did not significantly enhance the transfection activity.

\subsection{Effect of GALA}

The data shown in Figure 2 suggest that the endosomal escape of PEGylated NPs is impaired to a higher extent compared to cellular uptake. Consistent with this, the addition of Tf improved the activity only by several fold. Actually, the activity of Tf-modified PEGylated R8-MEND (RT-MEND) is still far below that of a non-PEGylated R8-MEND. We introduced the pH-sensitive fusogenic peptide GALA in the form of cholesterol-GALA (Chol-GALA) to enhance the endosomal escape of the RT-MEND. The inclusion of CholGALA in the lipid in the case of the R8-MEND resulted in a slight decrease in positive charge while this did not affect the surface charge in the case of the RT-MEND (Table 3). Interestingly, the presence of GALA dramatically improved gene expression by 430 fold in the case of the RT-MEND (Figure 4). Meanwhile, the use of GALA improved gene expression by $\sim 3$ fold in the case of the R8-MEND. This result is relatively consistent with the results shown in Figure 2, which show that endosomal escape is severely impaired in the case of the PEGylated R8-MEND but not to the same extent in the case of the R8MEND. As a result, the activity of GALA-containing Tf-modified R8-MEND (abbreviated as RTG-MEND) was comparable to the parent R8-MEND in terms of transfection activity (no statistically significant difference between R8-MEND and RTG-MEND). This means 
that the activity of R8-MEND that is lost by PEGylation could be fully restored by enhancing cellular uptake and more importantly by improving intracellular trafficking.

\subsection{Role of $R 8$}

We succeeded in achieving our main target, namely to restore the activity of R8MEND that is lost by PEGylation. However, we were also interested in investigating the role of R8 in the RTG-MEND system. We previously showed that the inclusion of CholGALA in the Tf-MEND system improved transfection activity by 10 fold. Here we show more than a 400-fold enhancement when chol-GALA is included in the RT-MEND system. This dramatic difference in the effect of GALA suggests that the presence of R8 greatly enhances the activity of GALA. To confirm this assumption and to examine the role of R8, we prepared a Tf-modified MEND lacking R8 and compared it with the MEND containing Tf and R8 or Tf and octalysine (K8) (with or without GALA). K8-MEND was prepared similar to R8-MEND except using stearylated octalysine (STR-K8) as a source of a positive

charge instead of STR-R8. The characteristics of the different systems are shown in Table 3. As shown in Figure 5, in the absence of GALA, the R8 improved the transfection activity of Tf-MEND by 2.5 folds while K8 did not cause a significant effect. This suggests the existence of a synergistic effect between R8 and Tf in enhancing cellular uptake. However, a dramatic difference was observed when combining Tf and R8 in the presence of GALA. The R8 improved the gene expression by 460 fold. The minor effect of GALA in the absence of R8 confirms our previous conclusion that R8 augments the activity of GALA. A similar high GALA effect could be observed in the case of the MEND modified with Tf and K8. However, the activity of the Tf/R8-MEND was higher than that of the Tf/K8- 
MEND (with or without GALA), indicating that the activity of R8 can only be partially explained by the presence of a positively charged peptide.

\subsection{Evaluation of targeting ability of different MENDs}

One of the main disadvantages of short arginine-rich peptides is the lack of specificity (Gupta et al., 2005). These peptides are able to bind to almost all types of cells owing to electrostatic interactions with cell surface negative constituents. However, the system developed in this study contains R8 covered with a PEG coat and Tf is attached to the tip of the PEG. Therefore, it would be expected that the internalization would mainly be mediated by Tf. To examine this assumption further, we transfected cells with different MENDs in the presence of excess free Tf in the transfection medium. As shown in Figure 6A, the gene expression in the case of RT-MEND and RTG-MEND was significantly inhibited by the

presence of free Tf. Under the same conditions, the gene expression was only slightly inhibited by free $\mathrm{Tf}$ in the case of the PEGylated R8-MEND without Tf (RP-MEND), although the difference was not statistically significant. The activity of R8-MEND without PEG was not inhibited by free Tf. Collectively; these findings indicate that Tf-modified MENDs are targeted to cells that are over-expressing Tf-Rs, despite having the positive R8 peptide in their makeup. To confirm this result, we compared the transfection activities of RTG-MEND in cancerous (HeLa) and non-cancerous (3T3-L1 and H9C2) cells. The activity in HeLa cells was significantly higher than that in non-cancerous cells (Figure 6B). The ratio of luciferase activities in HeLa to that in 3T3-L1 was $~ 90$ while it was $~ 10$ in the case of H9C2 cells. These ratios were much lower in the case of non-specific R8-MEND ( $~ 8$ in the case of 3T3-L1 and 1.7 in the case of H9C2 cells) (Supplementary Figure S1). 
This indicates that it is possible to overcome the non-specificity of the R8-MEND while the important role of R8 in intracellular trafficking is maintained.

\subsection{Effect of serum and comparison with Lipofectamine Plus reagent}

Since the prepared RTG-MEND is intended to decrease non-specific interactions with serum components, it was necessary to examine the effect of serum on transfection activity. The effect of serum on this process is shown in Figure 7 (expressed as \% transfection in the absence of serum). Transfection with the RTG-MEND in the presence of $10 \%$ serum was comparable to that in the absence of serum; however, activity was slightly reduced by the presence of $20 \%$ serum and reduced by $\sim 55 \%$ by the presence of $40 \%$ serum. We examined the effect of serum on the transfection activities of the Lipofectamine Plus reagent (LFPlus), one the most efficient commercially available systems for the transfection of pDNA in HeLa cells. The pattern of serum resistance of RTG-MEND was different from that of the LF-Plus reagent, which showed a $\sim 78 \%$ reduction in activity in the presence of $10 \%$ serum. The parent R8-MEND system showed a reduced transfection even in the presence of 10\% serum (Supplementary Figure S2). This shows that serum resistance in the case of the RTG-MEND is relatively higher than that of cationic transfection systems. The absolute value of the transfection efficiency of the RTG-MEND system is comparable to the LFPlus reagent in the presence of 10\% serum (Supplementary Figure S2). Finally, transfection with R8-MEND, RTG-MEND or LF-Plus reagent did not result in a significant effect on cell viability as judged by the total protein content in cell lysates at the end of the transfection (Supplementary Figure S2). 


\section{Discussion}

Although our previously developed R8-MEND produced high transfection activities in vitro and in vivo (Hayashi et al., 2011, 2012, Khalil et al., 2007, 2011), the presence of a high net positive charge results in a non-specific system that is highly taken up by the reticuloendothelial system (RES). In addition, positive systems interact with different cells and with negative serum components (Y. Zhang et al., 2012). In this study, we intended to optimize the R8-MEND system to decrease non-specific interactions and to increase its targeting ability. Nevertheless, the optimized system should ideally retain the high transfection activity of the parent system.

Cationic systems are generally modified with PEG to decrease non-specific interactions and to increase circulation time to allow tumor accumulation by the EPR effect. PEGylation has several advantages related to improving the extracellular movement of gene carriers and serum resistance; however, PEGylated systems are generally inefficient due to reduced interactions with cellular membranes in target cells (Hatakeyama et al., 2013). As a result, a system needs to be developed that combines both improved extracellular movement, serum resistance and high transfection activity. Several strategies have been developed to overcome this well characterized PEG dilemma (Hatakeyama et al., 2013). Some strategies focused mainly on using cleavable PEG derivatives that are specifically cleaved by enzymes or acid-catalyzed reactions at the target site (Ambegia et al., 2005; Hatakeyama et al., 2007). This effective de-PEGylation generates the parent system that can then efficiently transfect the target cells. In this study, we propose an 
alternative strategy in which the intrinsic activity of PEGylated systems can be improved without the need to remove PEG.

The R8-MEND used in this study showed a high transfection activity (Figure 1). Based on our previous analysis of cellular uptake and intracellular trafficking of a similar R8-MEND system, the R8 peptide enhanced cellular uptake mainly through endocytosis (Khalil et al., 2006b). After internalization, the R8-mediated close contact between the endosomal and liposomal membranes, which continues even after endosome acidification, facilitates the interaction between the two membranes (El-Sayed et al., 2008). Under acidic conditions, fusion activity between the DOPE-containing lipid envelope and the endosomal membrane facilitates the release of DNA cores to the cytosol. These cores provide additional protection of DNA against cytosolic enzymes and other degrading factors. It is clear that PEGylation interferes with one or more of these steps, since it dramatically reduces transfection activities (Figure 1). As per our strategy, we attempted to identify the reasons behind this PEG-mediated reduction in activity of R8-MEND in order to correct them. Deshpande et al. (2004) showed that PEGylation reduces the cellular uptake of lipoplexes. Meanwhile, Song et al. (2002) reported that only the endosomal escape of lipoplexes is impaired by PEGylation. Remaut et al. (2007) showed that PEGylation favors endosomal degradation of the delivered oligonucleotides. Due to this discrepancy, we needed to identify which step is impaired by PEGylation of the R8-MEND, i.e., cellular uptake, endosomal escape or both.

Our results show that both cellular uptake and endosomal escape are impaired by PEGylation of the R8-MEND, but the latter step is more severely impaired. This conclusion 
was based on measuring cellular uptake and transfection in the presence of the endosome disrupting agent chloroquine (Figure 2). PEGylation did not completely inhibit the cellular uptake since it was reduced by $~ 50 \%$ compared to R8-MEND. PEGylated R8-MEND showed a slight positive charge (ranging from 2.5 to 4.5) which may explain why the uptake is not severely impaired. However, the addition of Tf in a later step made the system negatively charged (Table 2), which is expected to limit the cellular uptake in cells not expressing Tf receptors. This is supported by the inhibition of the activity by around $80 \%$ in the presence of excess free $\mathrm{Tf}$ (Figure 6A). Furthermore, the activity is reduced to $1 \%$ in non-cancerous 3T3-L1 cells or to 13\% in H9C2 cells (Figure 6B). This supports our concept that the final system lost most of the non-specific cellular uptake of the original system.

The activity of the PEGylated R8-MEND was dramatically increased in the presence of chloroquine; however, the activity is less than that for a non-PEGylated R8-MEND by $\sim 8$ fold. While the effect of chloroquine may be more than just endosome disruption as previously suggested (Yang et al., 2009), we used chloroquine effect to roughly estimate the impaired step. The data shown in Figure 2 suggests that inefficient endosomal escape is a major reason for the reduced activity of the PEGylated R8-MEND. PEG may severely affect lipid exchange with the endosomal membrane, a critical step for efficient endosomal release. It is worth noting that we used a post-PEGylation strategy rather than prePEGylation. Actually, the use of the pre-PEGylated R8-MEND resulted in lower gene expression (data not shown). This is consistent with findings reported by Peeters et al. (2007) who showed that pre-PEGylated lipoplexes severely inhibit transfection. The 
authors attributed this reduced activity to inefficient and slower internalization as well as higher endosome entrapment compared to post-PEGylated lipoplexes. Peeters et al. used PEG-ceramides for post-PEGylation while we used DSPE-PEG. We favor using the latter since PEG-ceramides are believed to leave the lipoplexes upon contact with cell membranes (Peeters et al., 2007). In contrast, DSPE-PEG is more stably attached to the lipid and is not easily removed, which confirms the stealth property of the system.

To restore the activity of the R8-MEND that is lost by PEGylation, we first attempted to increase cellular uptake. The contribution of R8 to cellular uptake would be expected to be minimal, since the peptide is shielded with the PEG coat. Therefore, we needed an alternate molecule to be expressed on the outer surface of the system to enhance cellular uptake. This alternate structure should not be positively charged and preferably should be serum resistant. We suggested adding a targeting ligand to enhance cellular uptake and to add an active targeting ability to the system. We previously showed improved activities of systems modified with dual ligands including R8 and specific targeting ligands (Kibria et al., 2011; Takara et al., 2012). In this study, we used Tf, a well-known targeting ligand to cancer cells, which overly express Tf receptors. Several reports showed that the activity of cationic lipoplexes is improved by Tf modification (Sakaguchi et al., 2008; Singh et al., 2006; Tros De Ilarduya et al., 2002). As shown in Figure 3, the use of $\mathrm{Tf}$ resulted in a significant enhancement in gene expression when the amount of PEG used was $15 \mathrm{~mol} \%$ or lower. The Tf effect was not significant when higher amounts of PEG were used. We hypothesize that the high levels of PEG severely impaired endosomal escape. As a result, uptake may be significantly improved by $\mathrm{Tf}$ but the overall activity is not proportionally 
enhanced. The addition of Tf also added active targeting ability to the system (Figure 6). Therefore, the system would be expected to target tumor tissues by both passive and active mechanisms. Passive targeting arises from the dense PEG coat while the active targeting can be attributed to the presence of $\operatorname{Tf}$ on the outer layer of the system.

The activity of the RT-MEND was still lower than that of a non-PEGylated R8MEND. As shown in Figure 2, improving intracellular trafficking in the presence of PEG is an essentially required step. Therefore, we incorporated a $\mathrm{pH}$ sensitive fusogenic peptide GALA to enhance endosomal escape. GALA is used in the form of cholesterol-GALA to allow attachment of the peptide to the lipid envelope. We have previously demonstrated successful cytosolic release of the liposomal aqueous phase by the introduction of CholGALA (Kakudo et al., 2004). GALA is a synthetic, 30 amino acid peptide with a glutamic acid-alanine-leucine-alanine repeat. It converts from a random coil to an amphipathic $\alpha$ helix when the $\mathrm{pH}$ is reduced from 7.0 to 5.0. It is believed that the peptide forms a transbilayer pore responsible for enhancing endosomal escape (Li et al., 2004). The use of Chol-GALA dramatically enhanced the transfection activity of the PEGylated RT-MEND by more than 400 fold (Figure 4). Therefore, while PEG may inhibit endosomal escape resulting from DOPE-mediated fusion; it did not inhibit the activity of GALA. Interestingly, this dramatic effect of GALA was lost when R8 was not included in the system (Figure 5). This provides a clear demonstration of the indispensable role of R8 to achieving high transfection activity, even when it is shielded by PEG. One possible explanation is that the R8 peptide allows a close contact between liposomes and endosomal membranes, even in an acidic $\mathrm{pH}$ range. This close contact may augment the effect of GALA. In the absence of 
R8, Tf ligands are dissociated from Tf-R at acidic $\mathrm{pH}$ values, which may result in a low level of contact of liposomes with the endosomal membrane. We conclude that this design protected R8 against non-specific extracellular interactions, but allowed the peptide to augment GALA effect at the intracellular level. This control of the topology of the peptide is an important issue, in terms of the time and location where the peptide functions. The effect of R8 was higher than that of K8, a similar positively charged peptide. We previously investigated the superiority of R8 compared to K8 (El-Sayed et al., 2008). The role of R8 is further confirmed by previous reports showing a lower GALA effect in the absence of R8. For example, Sasaki et al. (2008) showed that Chol-GALA caused $~ 10$ fold enhancement in transfection activity of a Tf-MEND prepared in the absence of R8. In addition, Hatakeyama et al. (2007) showed that the silencing effect of a PEGylated siRNA system was not highly improved by Chol-GALA, unless a specific tumor-cleavable PEG was used. We believe the augmentation of GALA effect by a CPP is an important finding that may have future implications for the use of $\mathrm{pH}$ sensitive fusogenic peptides.

The optimized system described herein is protected with a dense PEG coat and carries a net negative charge, but still shows a high transfection activity that is comparable to Lipofectamine Plus reagent in the presence of $10 \%$ serum. In addition, the system has improved serum resistance and probably possess both passive and active targeting ability to tumor cells. We believe our proposed strategy will permit different targeting ligands to be combined with CPPs to target different tissues while maintaining high transfection activities. 


\section{Conclusion}

We report herein on a potential strategy for preparing CPP-based stealth systems with high transfection efficiencies and increased targeting characteristics. The strategy involves combining a CPP with a targeting ligand in a configuration that protects the former from non-specific interactions while allowing it to function at the intracellular level. The design also allows the targeting ligand to mediate specific cellular uptake in certain cells that express receptors for this ligand. Both functional devices proved to be important for achieving efficiency and targeting ability, provided that the system contains a device to improve intracellular trafficking. We developed a targeted, efficient, and serum resistant gene carrier that has a high potential for applications in the area of gene therapy. 


\section{Abbreviations:}

CHEMS, cholesteryl hemisuccinate; Chol-GALA, cholesterol GALA; DOPE, Dioleoyl phosphatidylethanolamine; DSPE-PEG, distearyl phosphatidylethanolaminepolyethyleneglycol 2000; DSPE-PEG-mal, maleimidic DSPE-PEG; DTT, dithiothleitol; K8, octalysine; LF-Plus, Lipofectamine Plus reagent; MEND, multifunctional envelope-type nanodevice; PDP-Tf, 3-(2-pyridinedithio)proprioyl Tf; PEG, polyethylene glycol; PEI, polyethyleneimine; PI, propidium iodide; R8, octaarginine; R8-Lip, R8-modififed liposomes; R8-MEND, R8-modified MEND; RT-MEND, Tf-modified PEGylated R8MEND; RTG-MEND, Tf-modified PEGylated R8-MEND with GALA; SDOC, sodium deoxycholate; SPDP, 3-(2-pyridyldithio) propionic acid N-hydroxysuccinimide ester; STRR8, stearylated R8; Tf, transferrin; Tf-R, Tf receptors; T-MEND, Tf-modified PEGylated MEND. 


\section{Acknowledgments}

This work was supported by the Special Education and Research Expenses from the

Ministry of Education, Culture, Sports, Science and Technology of Japan (MEXT). We thank Dr. Milton Feather for his helpful advice in editing this manuscript. 


\section{References}

Ambegia, E., Ansell, S., Cullis, P., Heyes, J., Palmer, L., MacLachlan, I., 2005. Stabilized plasmidlipid particles containing PEG-diacylglycerols exhibit extended circulation lifetimes and tumor selective gene expression. Biochim. Biophys. Acta - Biomembr. 1669, 155-163. doi:10.1016/j.bbamem.2005.02.001

Brooks, H., Lebleu, B., Vivès, E., 2005. Tat peptide-mediated cellular delivery: Back to basics. Adv. Drug Deliv. Rev. 57, 559-577. doi:10.1016/j.addr.2004.12.001

Cervia, L.D., Chang, C.C., Wang, L., Yuan, F., 2017. Distinct effects of endosomal escape and inhibition of endosomal trafficking on gene delivery via electrotransfection. PLoS One 12, 118. doi:10.1371/journal.pone.0171699

Collins, M., Thrasher, A., 2015. Gene therapy: progress and predictions. Proc R Soc B 282, 20143003. doi:10.1098/rspb.2014.3003

Deshpande, M.C., Davies, M.C., Garnett, M.C., Williams, P.M., Armitage, D., Bailey, L., Vamvakaki, M., Armes, S.P., Stolnik, S., 2004. The effect of poly(ethylene glycol) molecular architecture on cellular interaction and uptake of DNA complexes. J. Control. Release 97, 143-156. doi:10.1016/j.jconrel.2004.02.019

El-Sayed, A., Khalil, I.A., Kogure, K., Futaki, S., Harashima, H., 2008. Octaarginine- and octalysine-modified nanoparticles have different modes of endosomal escape. J. Biol. Chem. 283, 23450-23461. doi:10.1074/jbc.M709387200

Fonseca, S.B., Pereira, M.P., Kelley, S.O., 2009. Recent advances in the use of cell-penetrating peptides for medical and biological applications. Adv. Drug Deliv. Rev. 61, 953-964. doi:10.1016/j.addr.2009.06.001

Futaki, S., Suzuki, T., Ohashi, W., Yagami, T., Tanaka, S., Ueda, K., Sugiura, Y., 2001a. Argininerich peptides. An abundant source of membrane-permeable peptides having potential as 
carriers for intracellular protein delivery. J. Biol. Chem. 276, 5836-5840.

doi:10.1074/jbc.M007540200

Futaki, S., Ohashi, W., Suzuki, T., Niwa, M., Tanaka, S., Ueda, K., Harashima, H., Sugiura, Y., 2001b. Stearylated arginine-rich peptides: A new class of transfection systems. Bioconjug. Chem. 12, 1005-1011. doi:10.1021/bc015508l

Gupta, B., Levchenko, T.S., Torchilin, V.P., 2005. Intracellular delivery of large molecules and small particles by cell-penetrating proteins and peptides. Adv. Drug Deliv. Rev. 57, 637-651. doi:10.1016/j.addr.2004.10.007

Hatakeyama, H., Akita, H., Kogure, K., Harashima, H., 2007. Development of a novel systemic gene delivery system for cancer therapy with a tumor-specific cleavable PEG-lipid. Yakugaku Zasshi 127, 1549-1556. doi:10.1248/yakushi.127.1549

Hatakeyama, H., Akita, H., Harashima, H., 2013. The polyethyleneglycol dilemma: advantage and disadvantage of PEGylation of liposomes for systemic genes and nucleic acids delivery to tumors. Biol. Pharm. Bull. 36, 892-9. doi:10.1248/bpb.b13-00059

Hayashi, Y., Yamauchi, J., Khalil, I.A., Kajimoto, K., Akita, H., Harashima, H., 2011. Cell penetrating peptide-mediated systemic siRNA delivery to the liver. Int. J. Pharm. 419, 308313. doi:10.1016/j.ijpharm.2011.07.038

Hayashi, Y., Mizuno, R., Ikramy, K.A., Akita, H., Harashima, H., 2012. Pretreatment of hepatocyte growth factor gene transfer mediated by octaarginine peptide-modified nanoparticles ameliorates LPS/D-galactosamine-induced hepatitis. Nucleic Acid Ther. 22, 360-3. doi:10.1089/nat.2012.0352

Itaka, K., Kataoka, K., 2009. Recent development of nonviral gene delivery systems with virus-like structures and mechanisms. Eur. J. Pharm. Biopharm. 71, 475-483.

doi:10.1016/j.ejpb.2008.09.019 
Kakudo, T., Chaki, S., Futaki, S., Nakase, I., Akaji, K., Kawakami, T., Maruyama, K., Kamiya, H., Harashima, H., 2004. Transferrin-Modified Liposomes Equipped with a pH-Sensitive Fusogenic Peptide: An Artificial Viral-like Delivery System. Biochemistry 43, 5618-5628. doi:10.1021/bi035802w

Kamiya, H., Akita, H., Harashima, H., 2013. Pharmacokinetic and Pharmacodynamic Considerations in Gene Therapy. Drug Discov. Today 57, 990-996. doi:10.1128/AAC.0028713

Khalil, I.A., Futaki, S., Niwa, M., Baba, Y., Kaji, N., Kamiya, H., Harashima, H., 2004. Mechanism of improved gene transfer by the N-terminal stearylation of octaarginine: enhanced cellular association by hydrophobic core formation. Gene Ther. 11, 636-644. doi:10.1038/sj.gt.3302128

Khalil, I.A., Kogure, K., Akita, H., Harashima, H., 2006a. Uptake pathways and subsequent intracellular trafficking in nonviral gene delivery. Pharmacol. Rev. 58, 32-45. doi:10.1124/pr.58.1.8.32

Khalil, I.A., Kogure, K., Futaki, S., Harashima, H., 2006b. High density of octaarginine stimulates macropinocytosis leading to efficient intracellular trafficking for gene expression. J. Biol. Chem. 281, 3544-3551. doi:10.1074/jbc.M503202200

Khalil, I.A., Kogure, K., Futaki, S., Hama, S., Akita, H., Ueno, M., Kishida, H., Kudoh, M., Mishina, Y., Kataoka, K., Yamada, M., Harashima, H., 2007. Octaarginine-modified multifunctional envelope-type nanoparticles for gene delivery. Gene Ther. 14, 682-689. doi:10.1038/sj.gt.3302910

Khalil, I.A., Kogure, K., Futaki, S., Harashima, H., 2008. Octaarginine-modified liposomes: Enhanced cellular uptake and controlled intracellular trafficking. Int. J. Pharm. doi:10.1016/j.ijpharm.2007.12.003 
Khalil, I.A., Hayashi, Y., Mizuno, R., Harashima, H., 2011. Octaarginine- and pH sensitive fusogenic peptide-modified nanoparticles for liver gene delivery. J. Control. Release 156, 374-380. doi:10.1016/j.jconrel.2011.08.012

Kibria, G., Hatakeyama, H., Ohga, N., Hida, K., Harashima, H., 2011. Dual-ligand modification of PEGylated liposomes shows better cell selectivity and efficient gene delivery. J. Control. Release 153, 141-148. doi:10.1016/j.jconrel.2011.03.012

Kogure, K., Moriguchi, R., Sasaki, K., Ueno, M., Futaki, S., Harashima, H., 2004. Development of a non-viral multifunctional envelope-type nano device by a novel lipid film hydration method. J. Control. Release 98, 317-323. doi:10.1016/j.jconrel.2004.04.024

Kogure, K., Akita, H., Harashima, H., 2007. Multifunctional envelope-type nano device for nonviral gene delivery: Concept and application of Programmed Packaging. J. Control. Release 122, 246-251. doi:10.1016/j.jconrel.2007.06.018

Kogure, K., Akita, H., Yamada, Y., Harashima, H., 2008. Multifunctional envelope-type nano device (MEND) as a non-viral gene delivery system. Adv. Drug Deliv. Rev. 60, 559-571. doi:10.1016/j.addr.2007.10.007

Li, W., Nicol, F., Szoka, F.C., 2004. GALA: A designed synthetic pH-responsive amphipathic peptide with applications in drug and gene delivery. Adv. Drug Deliv. Rev. 56, 967-985. doi:10.1016/j.addr.2003.10.041

Mountain, A., 2000. Gene therapy: The first decade. Trends Biotechnol. doi:10.1016/S01677799(99)01416-X

Naldini, L., 2015. Gene therapy returns to centre stage. Nature 526, 351-360. doi:10.1038/nature15818

Peeters, L., Sanders, N.N., Jones, A., Demeester, J., De Smedt, S.C., 2007. Post-pegylated lipoplexes are promising vehicles for gene delivery in RPE cells. J. Control. Release 121, 
208-217. doi:10.1016/j.jconrel.2007.05.033

Remaut, K., Lucas, B., Braeckmans, K., Demeester, J., De Smedt, S.C., 2007. Pegylation of liposomes favours the endosomal degradation of the delivered phosphodiester oligonucleotides. J. Control. Release 117, 256-266. doi:10.1016/j.jconrel.2006.10.029

Sakaguchi, N., Kojima, C., Harada, A., Koiwai, K., Shimizu, K., Emi, N., Kono, K., 2008. Generation of highly potent nonviral gene vectors by complexation of lipoplexes and transferrin-bearing fusogenic polymer-modified liposomes in aqueous glucose solution. Biomaterials 29, 1262-1272. doi:10.1016/j.biomaterials.2007.11.016

Sasaki, K., Kogure, K., Chaki, S., Nakamura, Y., Moriguchi, R., Hamada, H., Danev, R., Nagayama, K., Futaki, S., Harashima, H., 2008. An artificial virus-like nano carrier system: Enhanced endosomal escape of nanoparticles via synergistic action of $\mathrm{pH}$-sensitive fusogenic peptide derivatives. Anal. Bioanal. Chem. 391, 2717-2727. doi:10.1007/s00216-008-2012-1

Sharma, G., Lakkadwala, S., Modgil, A., Singh, J., 2016. The Role of Cell-Penetrating Peptide and Transferrin on Enhanced Delivery of Drug to Brain. Int. J. Mol. Sci. 17. doi:10.3390/ijms17060806

Singh, M., Hawtrey, A., Ariatti, M., 2006. Lipoplexes with biotinylated transferrin accessories: Novel, targeted, serum-tolerant gene carriers. Int. J. Pharm. 321, 124-137. doi:10.1016/j.ijpharm.2006.05.005

Song, L.Y., Ahkong, Q.F., Rong, Q., Wang, Z., Ansell, S., Hope, M.J., Mui, B., 2002. Characterization of the inhibitory effect of PEG-lipid conjugates on the intracellular delivery of plasmid and antisense DNA mediated by cationic lipid liposomes. Biochim. Biophys. Acta - Biomembr. 1558, 1-13. doi:10.1016/S0005-2736(01)00399-6

Takara, K., Hatakeyama, H., Kibria, G., Ohga, N., Hida, K., Harashima, H., 2012. Size-controlled, dual-ligand modified liposomes that target the tumor vasculature show promise for use in 
drug-resistant cancer therapy. J. Control. Release 162, 225-232.

doi:10.1016/j.jconrel.2012.06.019

Torchilin, V., Levchenko, T., Rammohan, R., Volodina, N., Papahadjopoulos-Sternberg, B., D'Souza, G., 2003. Cell transfection in vitro and in vivo with nontoxic TAT peptide-liposomeDNA complexes. Proc Natl Acad Sci U S A 100, 1972-1977. doi:10.1073/pnas.04359061000435906100 [pii]

Tros De Ilarduya, C., Arangoa, M. a, Moreno-Aliaga, M.J., Düzgüneş, N., 2002. Enhanced gene delivery in vitro and in vivo by improved transferrin-lipoplexes. Biochim. Biophys. Acta 1561, 209-221. doi:10.1016/S0005-2736(02)00348-6

Tros de Ilarduya, C., Sun, Y., Düzgüneş, N., 2010. Gene delivery by lipoplexes and polyplexes. Eur. J. Pharm. Sci. 40, 159-170. doi:10.1016/j.ejps.2010.03.019

Yang, S., Coles, D.J., Esposito, A., Mitchell, D.J., Toth, I., Minchin, R.F., 2009. Cellular uptake of self-assembled cationic peptide-DNA complexes: Multifunctional role of the enhancer chloroquine. J. Control. Release 135, 159-165. doi:10.1016/j.jconrel.2008.12.015

Zhang, X.X., McIntosh, T.J., Grinstaff, M.W., 2012. Functional lipids and lipoplexes for improved gene delivery. Biochimie 94, 42-58. doi:10.1016/j.biochi.2011.05.005

Zhang, Y., Satterlee, A., Huang, L., 2012. In Vivo Gene Delivery by Nonviral Vectors: Overcoming Hurdles? Mol. Ther. 20, 1298-1304. doi:10.1038/mt.2012.79 


\section{Figure Legends}

\section{Figure 1}

\section{Transfection activities of different R8-MENDs}

HeLa cells were transfected with an R8-MEND containing luciferase-encoding pDNA and modified with different amounts of DSPE-PEG for $3 \mathrm{hr}$. The medium was then replaced with fresh medium plus serum and cells were incubated for a further $21 \mathrm{hr}$. At the end of the transfection, the cells were lysed and transfection activities were measured in the cell lysates (expressed as relative light units (RLU) per mg of protein). Each bar represents the mean of 3 different experiments, each performed in triplicate. Error bars show the S.D. $(* * \mathrm{P}<0.01)$

\section{Figure 2}

\section{Comparison of cellular uptake and the effect of chloroquine on transfection activities of R8-MEND or PEGylated R8-MEND}

A. Effect of PEG on the cellular uptake of R8-MEND. Different MENDs labeled with $1 \mathrm{~mol} \% \mathrm{DiD}$ were added to HeLa cells in the presence of $10 \%$ serum followed by incubation for $3 \mathrm{~h}$ before subjected to FACS analysis. Geo-mean fluorescence of cells is expressed as \% of that in the case of R8-MEND (means +/- S.D. of 3 different experiments) $\left({ }^{* *} \mathrm{P}<0.01\right.$, compared to R8-MEND). B. Effect of chloroquine on transfection activities. HeLa cells were transfected with pDNA encapsulated in R8-MEND or R8-MEND modified with 15 mol\% DSPE-PEG with or without the addition of chloroquine. Each bar 
represents the mean of 3 different experiments, each performed in triplicate. Error bars show the S.D. $(* \mathrm{P}<0.05$, compared to [-Chloroquine]).

\section{Figure 3}

\section{Effect of transferrin on transfection activities of different PEGylated R8-MENDs}

HeLa cells were transfected with pDNA encapsulated in different PEGylated R8MENDs with or without transferrin (Tf) for $3 \mathrm{hr}$. The medium was then replaced with fresh medium and the cells were incubated for a further $21 \mathrm{hr}$. Transfection activities are expressed as fold increase compared to non-Tf-modified R8-MEND. Each bar represents the mean of at least 3 different experiments, each performed in triplicate. Error bars show the SEM $(* \mathrm{P}<0.05$, compared to PEGylated R8-MEND without Tf).

\section{Figure 4}

\section{Effect of GALA on transfection activities of R8-MEND and RT-MEND}

HeLa cells were transfected with R8-MEND or PEGylated R8-MEND modified with Tf (RT-MEND) with or without GALA. Each bar represents the mean of at least 3 different experiments, each performed in triplicate. Error bars show the S.D. $\left({ }^{*} \mathrm{P}<0.05\right.$, compared to [-GALA]).

Figure 5

Comparison between MENDs containing $T f, T f / R 8$ or $T f / K 8$ in the presence or the absence of GALA 
HeLa cells were transfected with MENDs modified with Tf, Tf and R8 or Tf and K8 in the presence or the absence of GALA. Each bar represents the mean of at least 3 different experiments, each performed in triplicate. Error bars show the S.D. $\quad\left({ }^{*} \mathrm{P}<0.05\right.$ vs. Tf or $\mathrm{Tf}+\mathrm{K} 8$ )

\section{Figure 6}

\section{Evaluation of targeting ability and selectivity of different MENDs}

A. Effect of free Tf on transfection activities of different MENDs. HeLa cells were transfected with R8-MEND, PEGylated R8-MEND (RP-MEND), Tf modified R8-MEND with or without GALA (RTG-MEND or RT-MEND, respectively). Transfection was performed in the absence or the presence of free $\mathrm{Tf}$ for $1 \mathrm{hr}$. The medium was then replaced with fresh medium and cells were further incubated for 23 hr. Transfection activities are expressed as percent of control (in the absence of free Tf) in each case. Each bar represents the mean of 3 different experiments, each performed in duplicate. Error bars show the S.E.M $\left({ }^{* *} \mathrm{P}<0.01\right.$, compared to [- free Tf]). B. Comparing transfection activities of RTGMEND in cancerous and non-cancerous cell lines. Transfection was performed for $3 \mathrm{hr}$ in the presence of medium supplemented with $10 \%$ serum as previously described. Each bar represents the mean of 3 different experiments, each performed in triplicate. Error bars show the S.D. (**P<0.01, compared to [HeLa cells]).

\section{Figure 7}

\section{Effect of serum on transfection activities}


HeLa cells were transfected with R8-MEND modified with Tf and GALA (RTGMEND) or pDNA complexed with Lipofectamine Plus reagent (LF-Plus) in the presence or the absence of different serum amounts for $3 \mathrm{hr}$. The medium was then replaced with fresh medium plus $10 \%$ serum and cells were further incubated for $21 \mathrm{hr}$. At the end of transfection, cells were lysed and transfection activities were measured in the cell lysates (expressed as percent of transfection activities in the absence of serum). Values are the means of at least 3 different experiments, each performed in triplicate. Error bars show the S.D. $\left({ }^{*} \mathrm{P}<0.05,{ }^{* *} \mathrm{P}<0.01\right.$, compared to serum-free transfection). 


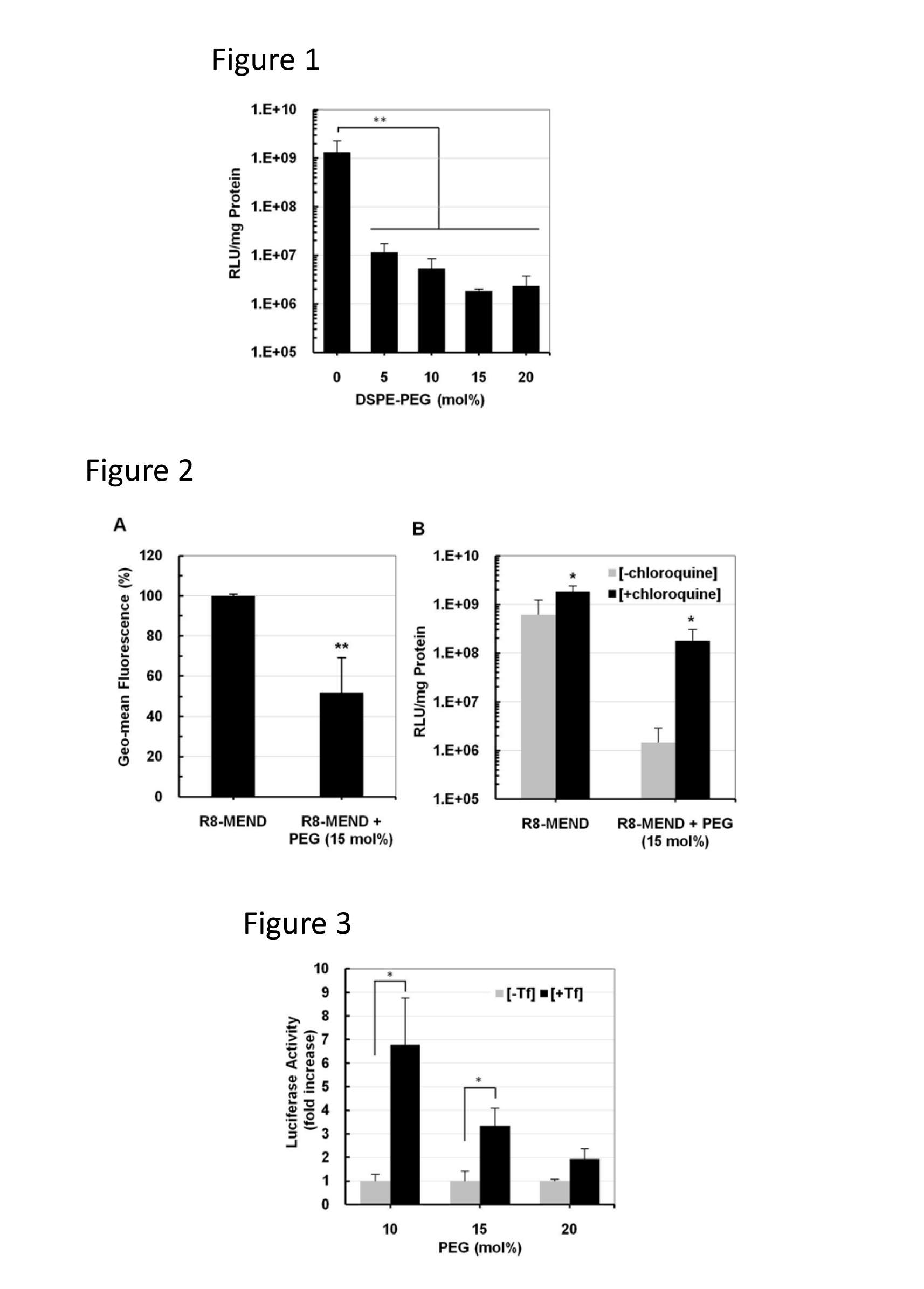


Figure 4

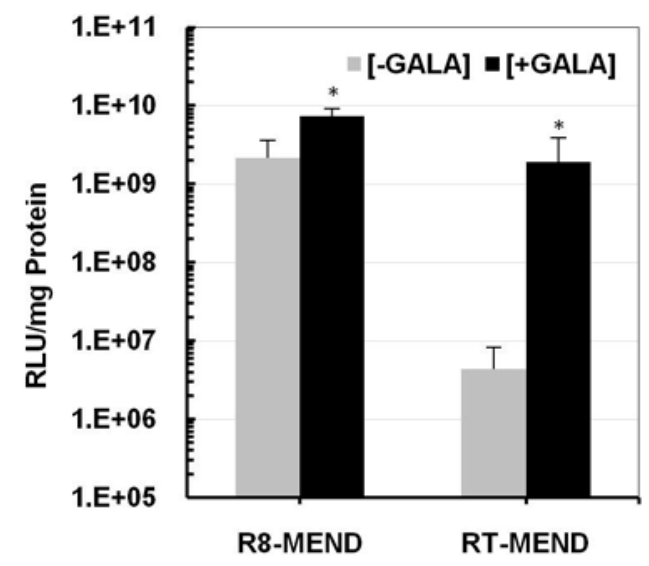

Figure 5

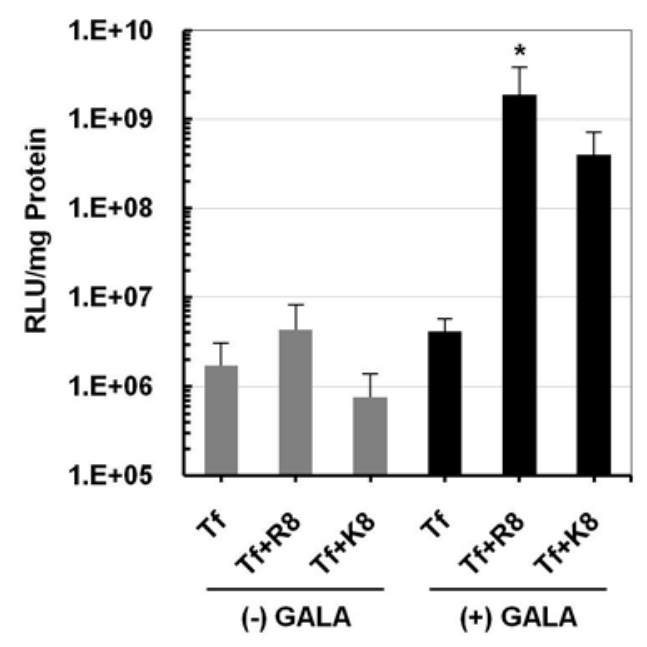

Figure 6
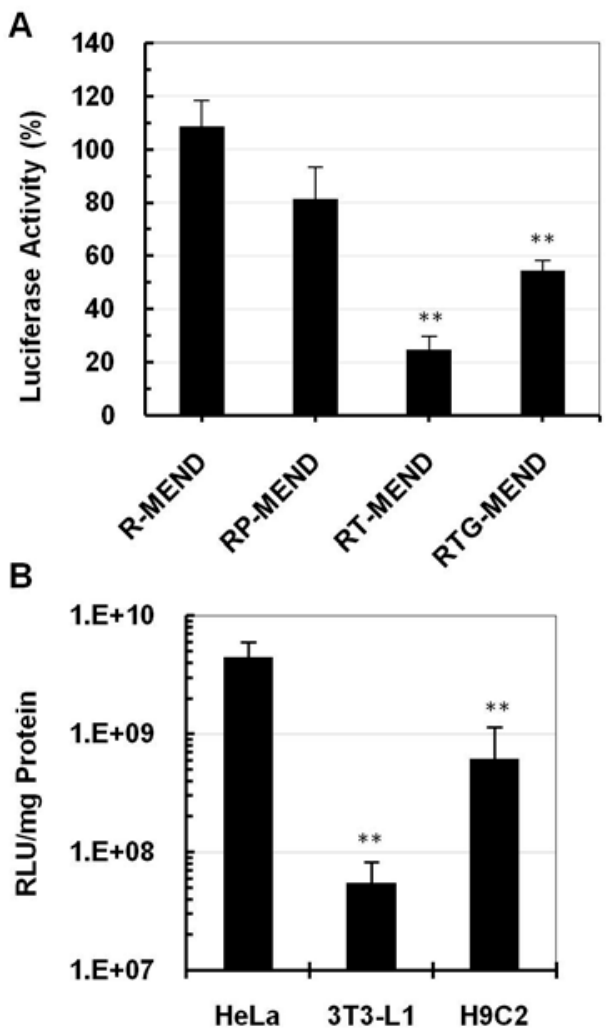


\section{Figure 7}

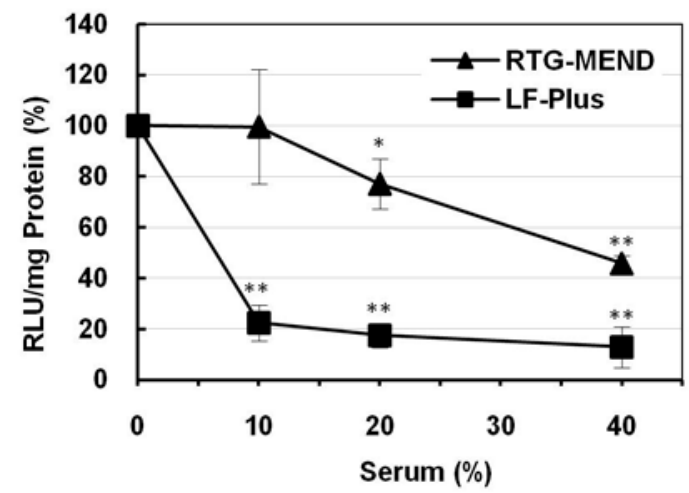

\section{Graphical Abstract}

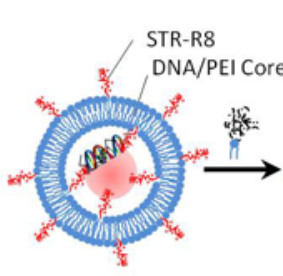

R8-MEND

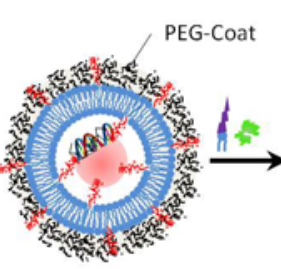

RP-MEND

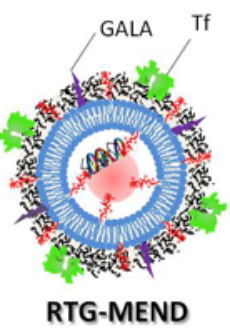

PEG shielding dramatically reduced the high transfection activities of R8-MEND. The efficiency could be fully restored by adding Transferrin (Tf), to restore cellular uptake, and a pH-sensitive fusogenic peptide (GALA), to improve endosomal escape.
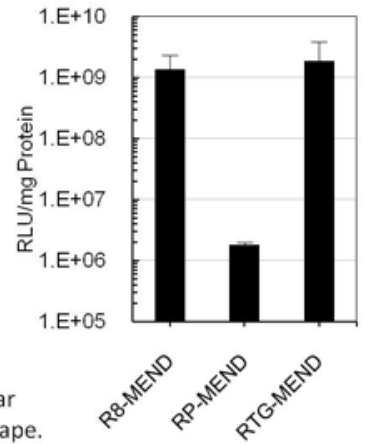
Table 1

Characterization of R8-MENDs with or without DSPE-PEG

\begin{tabular}{lcc}
\hline & $\begin{array}{c}\text { Diameter } \\
(\mathrm{nm})^{\mathrm{a}}\end{array}$ & $\begin{array}{c}\text { Zeta potential } \\
(\mathrm{mV})^{\mathrm{a}}\end{array}$ \\
\hline Plasmid DNA/PEI core & $88 \pm 6$ & $-25 \pm 8$ \\
R8-MEND & $261 \pm 21$ & $41 \pm 3$ \\
R8-MEND + PEG 5 mol\% & $208 \pm 21$ & $21 \pm 4$ \\
R8-MEND + PEG 10 mol\% & $216 \pm 41$ & $9 \pm 3$ \\
R8-MEND + PEG 15 mol\% & $218 \pm 16$ & $4 \pm 1$ \\
R8-MEND + PEG 20 mol\% & $224 \pm 29$ & $-3 \pm 5$ \\
\hline
\end{tabular}

${ }^{\mathrm{a}}$ Data are mean \pm S.D. of at least 3 different preparations

Table 2

Characterization of different PEGylated R8-MENDs with or without transferrin (Tf)

\begin{tabular}{cccc}
\hline $\begin{array}{c}\text { PEG } \\
(\mathrm{mol} \%)\end{array}$ & Tf & $\begin{array}{c}\text { Diameter } \\
(\mathrm{nm})^{\mathrm{a}}\end{array}$ & $\begin{array}{c}\text { Zeta potential } \\
(\mathrm{mV})^{\mathrm{a}}\end{array}$ \\
\hline 10 & - & $199 \pm 9$ & $7 \pm 4$ \\
& + & $179 \pm 2$ & $-15 \pm 3$ \\
15 & - & $184 \pm 2$ & $1 \pm 5$ \\
& + & $180 \pm 6$ & $-17 \pm 1$ \\
20 & - & $181 \pm 8$ & $-2 \pm 1$ \\
& + & $183 \pm 7$ & $-18 \pm 6$ \\
\hline
\end{tabular}

${ }^{\mathrm{a}}$ Data are mean \pm S.D. of at least 3 different preparations

Table 3

Characterization of different MENDs prepared with or without GALA

\begin{tabular}{cccc}
\hline & GALA & $\begin{array}{c}\text { Diameter } \\
(\mathrm{nm})^{\mathrm{a}}\end{array}$ & $\begin{array}{c}\text { Zeta potential } \\
(\mathrm{mV})^{\mathrm{a}}\end{array}$ \\
\hline \multirow{2}{*}{ R8-MEND } & - & $274 \pm 71$ & $46 \pm 5$ \\
& + & $217 \pm 4$ & $41 \pm 4$ \\
\hline R8-Tf-MEND & - & $177 \pm 4$ & $-17 \pm 1$ \\
(RT-MEND) & + & $205 \pm 4$ & $-17 \pm 3$ \\
\hline Tf-MEND & - & $152 \pm 26$ & $-24 \pm 5$ \\
(T-MEND) & + & $159 \pm 7$ & $-31 \pm 3$ \\
\hline K8-Tf-MEND & - & $202 \pm 26$ & $-18 \pm 3$ \\
(KT-MEND) & + & $217 \pm 11$ & $-19 \pm 2$ \\
\hline
\end{tabular}

${ }^{\mathrm{a}}$ Data are mean \pm S.D. of at least 3 different preparations 


\section{Supplementary Figure S1}
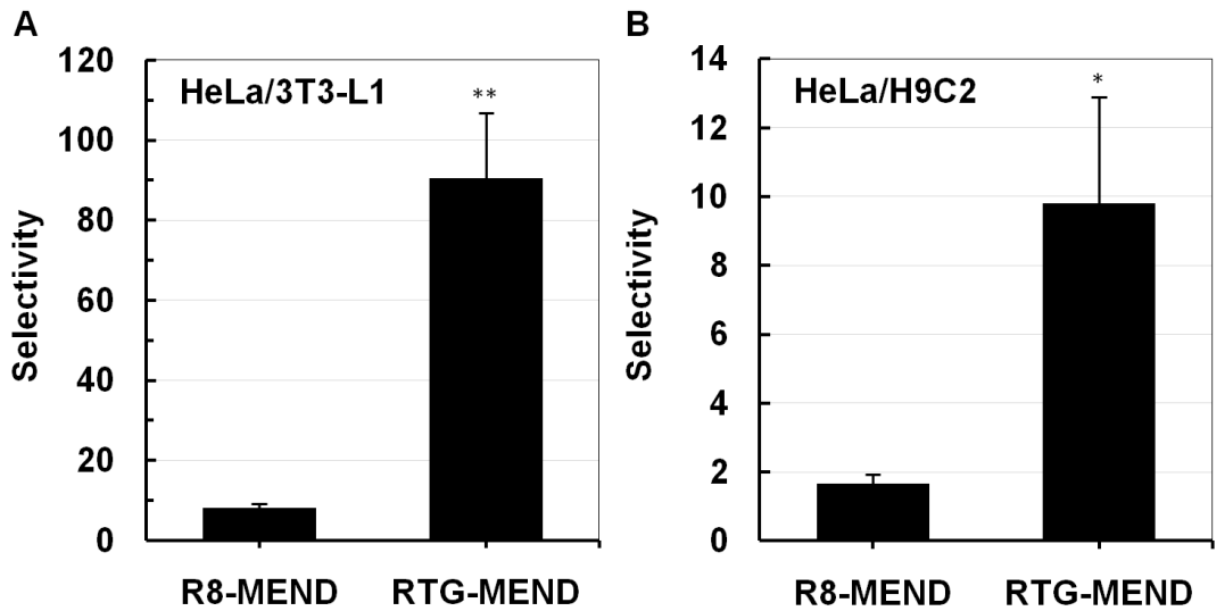

Transfection activities of R8-MEND or RTG-MEND were evaluated in 3 different cell lines (HeLa, 3T3-L1 and H9C2). Transfection was performed for $24 \mathrm{hr}$ in the presence of 10\% serum. Selectivity was estimated by calculating the ratio of luciferase activity in the case of cancerous (HeLa cells) to non-cancerous (3T3-L1 or H9C2 cells). Each bar represents the mean of 3 different experiments, each performed in triplicate. Error bars show the S.D. $(* \mathrm{P}<0.05$, $* * \mathrm{P}<0.01$, compared to [R8-MEND]). 


\section{Supplementary Figure S2}

A

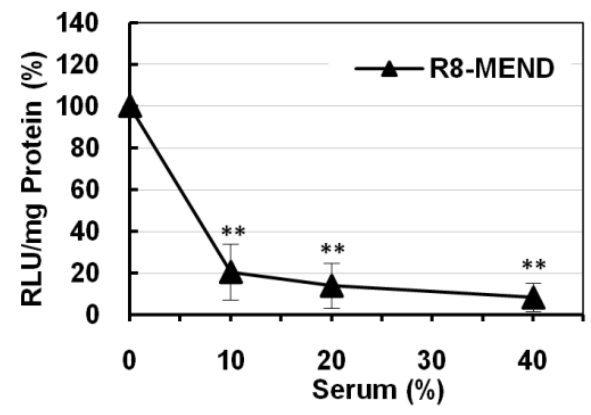

B

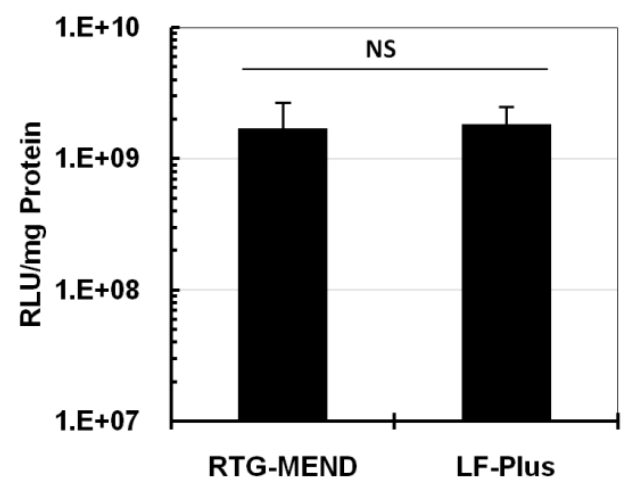

C

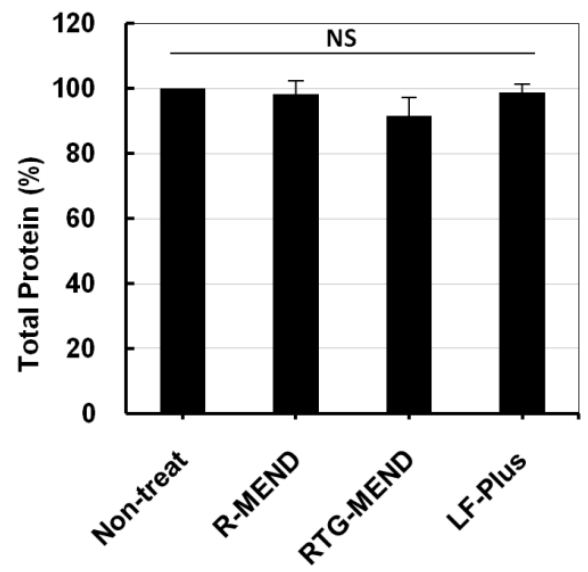

A. Effect of serum on transfection activities of R8-MEND. HeLa cells were transfected with R8MEND in the presence or the absence of different serum amounts. Transfection activities are expressed as percent of transfection activities in the absence of serum. Values are the means of 3 different experiments, each performed in triplicate. Error bars show the S.D. $(* * \mathrm{P}<0.01$, compared to serum-free transfection).

B. Absolute values of transfection activities of RTG-MEND and Lipofectamine Plus reagent in the presence of $10 \%$ serum (data from Figure 7). Each bar represents the mean of at least 3 different experiments, each performed in triplicate. Error bars show the S.D. (NS is nonsignificant).

C. Total protein content of cells after transfection with different MENDs or with Lipofectamine Plus reagent. Total proteins are expressed as \% of non-treated cells. Each bar represents the mean of at least 3 different experiments, each performed in triplicate. Error bars show the S.D. (NS is non-significant). 